\title{
Ultrasound and Doppler-Guided Surgery for the Treatment of Jumper's Knee in Professional Rugby Players
}

\author{
Håkan Alfredson 1,2,3*, Lorenzo Anthony Masci3 ${ }^{3}$ \\ ${ }^{1}$ Department of Surgical and Perioperative Science, Sports Medicine Unit, Umeå University, Umeå, Sweden \\ ${ }^{2}$ ISEH, University College London Hospitals, London, UK \\ ${ }^{3}$ Pure Sports Medicine Clinic, London, UK \\ Email: "hakan.alfredson@umu.se
}

Received 10 November 2014; revised 17 December 2014; accepted 7 January 2015

Copyright (C) 2015 by authors and Scientific Research Publishing Inc.

This work is licensed under the Creative Commons Attribution International License (CC BY). http://creativecommons.org/licenses/by/4.0/

(c) (i) Open Access

\begin{abstract}
Background: Jumper's knee is relatively common among rugby players, and treatment of this condition is known to be difficult. Intra-tendinous revision surgery has shown poor results. New research on innervation patterns, and a new US+DP-guided treatment method targeting the regions with vessels and nerves outside the tendon has shown promising results in patients with Jumper's knee. Material: This study includes 12 patellar tendons from 9 professional rugby players (mean age 26 years) with a long duration (range 12 - 72 months) of pain from the proximal patellar tendon. For 3 tendons there was previously intra-tendinous revision surgery with a poor result. Method: Treatment with Ultrasound (US) and Doppler (DP)-guided arthroscopic shaving + open scraping, followed by immediate weight bearing and gradually increased loading up to full loading after 6 - 8 weeks, was performed. Results: For 9 tendons there was a good clinical result, and all returned to full professional rugby within 4 - 6 months. The mean VISA score increased from 49 to $78(\mathrm{p}<0.05)$. Follow-ups (range 10 - 30 months) show remaining good results. For 3 tendons, all have had previous intra-tendinous revision surgery, the clinical results were poor and they couldn't return to rugby. Conclusions: The short-term results in this relatively small material indicate that US+DP-guided arthroscopic shaving + open scraping is a good treatment method for professional rugby players with chronic painful Jumper's knee.
\end{abstract}

\section{Keywords}

Jumper's Knee, Patellar Tendinopathy, Rugby, Surgical Treatment, Ultrasound + Doppler

\footnotetext{
${ }^{*}$ Corresponding author.
} 


\section{Introduction}

The aetiology and pathogenesis to Jumper's knee/patellar tendinopathy are unknown, but the condition is considered to be an overuse injury of the knee joint extensor mechanism [1]. The condition is common in jumping and also relatively common in other sports involving explosive leg activity [2] [3]. Rugby is a sport involving explosive leg activity during fast runs, for certain players also jumping, and in training lots of weightlifting. During weightlifting, the patellar tendon has been demonstrated to be exposed to very high forces (up to 17 times the body weight) [4].

Jumper's knee is known to be difficult to treat [1] [5] [6]. Non-surgical treatment methods require long periods of rehabilitation and the results are often not fully satisfactory [5] [6]. Surgical treatment has shown varying clinical results [7]-[9]. In a randomized controlled study, the traditional surgical treatment with tenotomy and excision of abnormal tendon tissue, followed by a long rehabilitation period, show good results only in $50 \%$ of the patients [9]. With these poor results, there has been a need for more research and new treatment methods. Recent research on tissue specimens has shown few, if any, nerves inside the tendinopathy tendon, but multiple nerves in close relation to blood vessels on the deep (dorsal) side of the tendon [10] [11]. These findings correspond to regions with high blood flow on US+DP examination. Also, from athletes involved in contact sports (ground contact and opponent contact) where US+DP showed a local thickening of the paratenon including high blood flow, tissue specimens have shown similar findings with multiple nerves in close relation to blood vessels outside the tendon (non published material). A recently invented surgical treatment method, ultrasound and Doppler- guided arthroscopic shaving, has shown very promising clinical results [12] [13]. With this method the surgical treatment is performed outside the tendon (no tenotomy), allowing for a quick postoperative rehabilitation. For patients having changes also on the superficial side, the arthroscopic procedure is combined with an open scraping procedure on the superficial side of the tendon.

The aim with this prospective study was to follow the clinical results after treatment with ultrasound and Doppler-guided arthroscopic shaving + open scraping in professional rugby players suffering from chronic painful Jumper's knee.

\section{Material and Methods}

Nine professional rugby players (mean age 26 years, range 21 - 34) with a long duration (12 - 72 months) of pain in the proximal part of 12 patellar tendons, diagnosed as Jumper's knee, were included. For 3 tendons there was previously intra-tendinous revision surgery with a poor result.

\section{Surgery: Ultrasound-guided arthroscopic shaving [12] + open scraping}

Ultrasound and Colour Doppler was used pre-operatively to verify the changes.

For all patients: There was a thickening of the proximal patellar tendon with structural tendon changes regions with hypo-echoicity located mainly on the deep side and central in the tendon. There was a localised high blood flow outside and inside the deep side of the tendon. On the superficial side there were regions with thickened paratenon containing localised high blood flow (Figure 1).

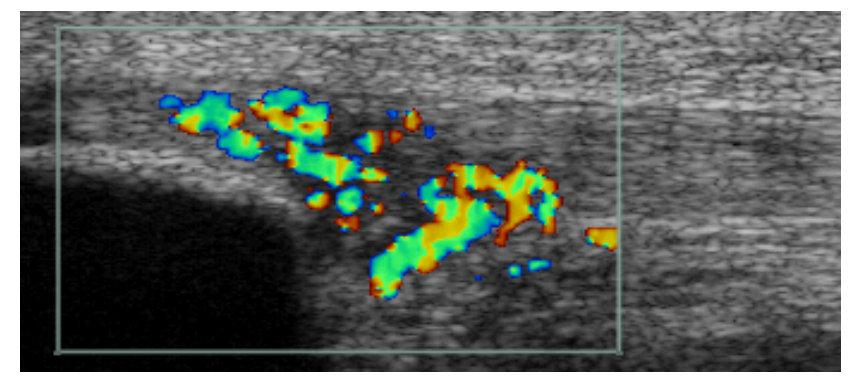

Figure 1. Ultrasound + Doppler examination of a patient with a thickening of the proximal patellar tendon, structural tendon changes including regions with hypo-echoicity located mainly on the deep side and central, a localised high blood flow outside and inside the deep side and central part of the tendon. On the superficial side there are regions with thickened paratenon with high blood flow in paratenon and inside superficial part of the tendon. 
The US and DP findings guided the surgical treatment on both sides of the tendon.

Arthroscopy was performed in general or local anaesthesia. The patients were in a supine position with straight knee and relaxed quadriceps. Standard antero-medial and antero-lateral portals. Pressure controlled pump. Tourniquet was used if general anaestesia. The patellar tendon insertion into the patella was identified. For shaving, a $4.5 \mathrm{~mm}$ full radius blade shaver was used. Simultaneous ultrasound examination (longitudinal and transversal views) guided the procedure. Careful shaving, aiming to destroy only the region with high blood flow (neovessels) and nerves adjacent to the tendinosis changes on the dorsal side of the tendon, was done (i.e. separating the Hoffa fat pad from the patellar tendon). No tendon tissue was resected, and the Hoffa fat pad was saved. There was a careful inspection of the tip of the patella, and if there was a sharp edge of the patellar tip, indicating interference between the patellar tip and the tendon, the tip of the patella was smoothened off with the shaver. A standard arthroscopic evaluation of the whole knee joint ended the arthroscopical procedure. The portals were sutured, and $20 \mathrm{ml}$ of Chirocain was injected into the knee joint.

An open procedure was used for treatment of the superficially located changes. Via a central longitudinal incision (in the region with US+DP verified changes) through the skin, bursa and paratenon, the superficial side of the tendon was visualized. Thickened paratenon was excised, and the underlaying vascularised fatty infiltration was carefully scraped away until normal underlaying tendon. Hemostasis. Resorbable sutures subcutaneously, and non-resorbable sutures in the skin. Bandage from toes to above knee level, with local compression on superficial wound.

\section{After treatment}

Day 1: After surgery the patients rested over night, then they were allowed full weight bearing walking.

Week 1 - 2: Range of movement exercises, quadriceps innervation training and gradually increased walking. Light biking from second week.

Week 3 - 6: Gradually increased patellar tendon loading, depending on effusion, muscular fitness and pain symptoms.

Week: 7 - 12: If no complications, gradually increased loading in rugby training and playing.

\section{Follow-ups}

After treatment most patients were followed up at 6 - 8 weeks postoperatively.

Further follow-ups were done via mail contact with the team physiotherapist or the patient.

\section{Outcomes}

The primary outcome measure was to evaluate the clinical effect of the treatment by having the patients to score on a VISA-P score, before and after treatment.

\section{Results}

For 9 tendons (7 patients) there was a good clinical result, and all returned to full professional rugby within 4 - 6 months.

The mean VISA score increased significantly from 49 before treatment to 78 after treatment (range 59 - 90) $(\mathrm{p}<0.05)$.

Follow-ups ranging from 10 - 30 months after treatment, showed remaining good clinical results.

For 3 tendons ( 2 patients), all had previously been treated with intra-tendinous revision surgery, the clinical results were poor and they couldn't return to professional rugby training and playing.

\section{Discussion}

The clinical results from this study indicate that US+DP-guided arthroscopic shaving + open scraping is a good treatment method for professional rugby players with chronic painful Jumper's knee, but players that previously had undergone intra-tendinous revision surgery for the same diagnosis had poor outcomes.

It is, of course, important to notice that this is a small patient material, and that the follow-up time is short. On the other hand, the results are similar to the results demonstrated in a recent 4-year follow-up study on athletes from different sports [14].

For all 9 tendons that had not had surgical treatment before there was a good clinical result, and all these patients returned to full rugby training and playing. However, looking at the VISA scores, even though the average score was high, there was a variation indicating that all patients were not pain-free. Anyhow, they could participate in full training and playing which they couldn't do before the surgical treatment. There was also an individual 
variation in how early they could return to playing matches, one patient that had bilateral surgery (3 days between the operations) returned to match play already after 8 weeks, while another patient that had unilateral surgical treatment couldn't return to match play until 5 months after surgery.

The methodology used for the surgical treatment is based on new research findings related to the innervation patterns in the chronic painful patellar tendon [10] [11]. The relationship between nerves and blood vessels (high blood flow) has been studied [15] to try to answer the question where the pain comes from [16], and used to invent new successful treatment methods targeting the regions with high blood flow and nerves outside the tendons [12]-[14] [17]-[19]. During the treatment, the procedure target the regions with localized high blood flow in close relation to regions with tendon (deep side) and paratenon (superficial side) changes, and the tendon inside is never touched. This allows for a relatively fast return to tendon loading activity after surgery. Using this methodology we have had very few complications.

It was interesting to notice that the 3 tendons that previously had been surgically treated with intra-tendinous revision surgery had a poor outcome. It can be speculated if there, in contrast to tendons that had not had intra-tendinous surgery [11], are nerves inside these tendons? We have had similar poor results also in a few other tendons that previously had had intra-tendinous revision surgery, and we have on-going research with analyses of tendon tissue specimens, to examine if there is a different innervation pattern in these tendons. The previously most commonly used surgical treatment method for this condition was intra-tendinous revision surgery, but because of relatively poor clinical results [7]-[9] this method has been more and more abandoned. Also, intra-tendinous surgery requires a careful and long rehabilitation period, and even if diminished tendon pain, for high level athletes it is difficult to be able to return to previous sport competition level if having been away too long. With the new scientific knowledge about the innervation patterns in the chronic painful patellar tendon [10] [11], it seems not to be indicated to use intra-tendinous revision surgery for the previously not surgically treated proximal patellar tendinopathy tendon.

For diagnosis we used US+DP, that has been shown to be a reliable method to study especially superficial tendons [20]. Our research group has a long tradition and experience from using this technique to evaluate tendons, and we feel confident to provide an accurate diagnosis. Also, we have since around 15 years used US+DP to guide surgical procedure in the Achilles [19] and patellar tendons [13] [14] [18].

\section{Conclusion}

In conclusion, the short-term results in this relatively small material indicate that US+DP-guided arthroscopic shaving + open scraping is a good treatment method for professional rugby players with chronic painful Jumper's knee that had not been surgically treated before. Larger materials with longer follow-ups are needed before further conclusions can be drawn.

\section{References}

[1] Khan, K.M., Maffuli, N., Coleman, B.D., Cook, J.L. and Taunton, J.E. (1998) Patellar Tendinopathy: Some Aspects of Basic Science and Clinical Management. British Journal of Sports Medicine, 32, 346-355. http://dx.doi.org/10.1136/bjsm.32.4.346

[2] Ferretti, A., Papandrea, P. and Conteduca, F. (1990) Knee Injures in Volleyball. Sports Medicine, 10, $132-138$. http://dx.doi.org/10.2165/00007256-199010020-00006

[3] Lian, O.B., Engebretzen, L. and Bahr, R. (2005) Prevalence of Jumper's Knee among Elite Athletes from Different Sports: A Cross Sectional Study. The American Journal of Sports Medicine, 33, 561-567. http://dx.doi.org/10.1177/0363546504270454

[4] Zernicke, R.F., Garhammer, J. and Jobe, F.W. (1977) Human Patellar Tendon Rupture: A Kinetic Analysis. Journal of Bone and Joint Surgery (Am), 59, 179-183.

[5] Cook, J.L., Khan, K.M., Harcourt, P.R., Grant, M., Young, D.A. and Bonar, S.F. (1997) A Cross Sectional Study of 100 Athletes with Jumper's Knee Managed Conservatively and Surgically. British Journal of Sports Medicine, 31, 332-336. http://dx.doi.org/10.1136/bjsm.31.4.332

[6] Cook, J.L. (2001) What's the Appropriate Treatment for Patellar Tendinopathy? British Journal of Sports Medicine, 35, 291-294. http://dx.doi.org/10.1136/bjsm.35.5.291

[7] Coleman, B.D., Khan, K.M., Kiss, Z.S., Bartlett, J., Young, D.A. and Wark, J.D. (2000) Open and Arthroscopic Patellar Tenotomy for Chronic Patellar Tendinopathy. A Retrospective Outcome Study. Victorian Institute of Sport Tendon Study Group. The American Journal of Sports Medicine, 28, 183-190. 
[8] Coleman, B.D., Khan, K.M., Maffulli, N., Cook, J.L. and Wark, J.D. (2000) Studies of Surgical Outcome after Patellar Tendinopathy: Clinical Significance of Methodological Deficiencies and Guidelines for Future Studies. Scandinavian Journal of Medicine \& Science in Sports, 10, 2-11. http://dx.doi.org/10.1034/j.1600-0838.2000.010001002.x

[9] Bahr, R., Fossan, B., Løken, S. and Engebretsen, L. (2006) Surgical Treatment Compared with Eccentric Training for Patellar Tendinopathy (Jumpers Knee). A Randomized Controlled Trial. J Bone Joint Surg Am., 88, 1689-1698.

[10] Danielsson, P., Alfredson, H. and Forsgren, S. (2006) Distribution of General (PGP 9.5) and Sensory (Substance P/CGRP) Innervations in the Human Patellar Tendon. Knee Surgery, Sports Traumatology, Arthroscopy, 14, 125-132. http://dx.doi.org/10.1007/s00167-005-0636-7

[11] Danielsson, P., Andersson, G., Alfredson, H. and Forsgren, S. (2008) Marked Sympathetic Component in the Perivascular Innervation of the Dorsal Paratendinous Tissue of the Patellar Tendon in Arthroscopically Treated Tendinosis Patients. Knee Surgery, Sports Traumatology, Arthroscopy, 16, 621-626. http://dx.doi.org/10.1007/s00167-008-0530-1

[12] Willberg, L., Sunding, K., Öhberg, L., Forsblad, M. and Alfredson, H. (2007) Treatment of Jumper’s Knee: Promising Short-Term Results in a Pilot Study Using a New Arthroscopic Approach Based on Imaging Findings. Knee Surgery, Sports Traumatology, Arthroscopy, 15, 676-681. http://dx.doi.org/10.1007/s00167-006-0223-6

[13] Willberg, L., Sunding, K., Forssblad, M., Fahlstrom, M. and Alfredson, H. (2011) Sclerosing Polidocanol Injections or Arthroscopic Shaving to Treat Patellar Tendinopathy/Jumper's Knee? A Randomised Controlled Study. British Journal of Sports Medicine, 45, 411-415. http://dx.doi.org/10.1136/bjsm.2010.082446

[14] Willberg, L., Sunding, K., Forssblad, M., Fahlstrom, M. and Alfredson, H. (2014) Sclerosing Injections and Ultrasound-Guided Arthroscopic Shaving for Patellar Tendinopathy-Good Clinical Results and Decreased Tendon Thickness after Surgery-A Medium Term Follow-Up Study. Knee Surgery, Sports Traumatology, Arthroscopy. [Epub ahead of print]

[15] Alfredson, H., Öhberg, L. and Forsgren, S. (2003) Is Vasculo-Neural Ingrowth the Cause of Pain in Chronic Achilles Tendinosis?-An Investigation Using Ultrasonography and Colour Doppler, Immunohistochemistry, and Diagnostic Injections. Knee Surgery, Sports Traumatology, Arthroscopy, 11, 334-338. http://dx.doi.org/10.1007/s00167-003-0391-6

[16] Khan, K.M., Cook, J.L., Maffuli, N. and Kannus, P. (2000) Where Is the Pain Coming from in Tendinopathy? It May Be Biochemical, Not Only Structural, in Origin. British Journal of Sports Medicine, 34, 81-83. http://dx.doi.org/10.1136/bjsm.34.2.81

[17] Alfredson, H. and Öhberg, L. (2005) Neovascularisation in Chronic Painful Patellar Tendinosis Promising Results after Sclerosing Neovessels outside the Tendon Challenges the Need for Surgery. Knee Surgery, Sports Traumatology, Arthroscopy, 13, 74-80. http://dx.doi.org/10.1007/s00167-004-0549-x

[18] Hoksrud, A., Öhberg, L. Alfredson, H. and Bahr, R. (2006) Ultrasound-Guided Sclerosis of Neovessels in Painful Chronic Patellar Tendinopathy_A Randomized Controlled Trial. The American Journal of Sports Medicine, 34, 17381746. http://dx.doi.org/10.1177/0363546506289168

[19] Alfredson, H. (2011) Ultrasound and Doppler-Guided Mini-Surgery to Treat Midportion Achilles Tendinosis: Results of a Large Material and a Randomised Study Comparing Two Scraping Techniques. British Journal of Sports Medicine, 45, 407-410. http://dx.doi.org/10.1136/bjsm.2010.081216

[20] Weinberg, E.P., Adams, M.J. and Hollenberg, G.M. (1998) Color Doppler Sonography of Patellar Tendinosis. American Journal of Roentgenology, 171, 743-744. http://dx.doi.org/10.2214/ajr.171.3.9725308 
Scientific Research Publishing (SCIRP) is one of the largest Open Access journal publishers. It is currently publishing more than 200 open access, online, peer-reviewed journals covering a wide range of academic disciplines. SCIRP serves the worldwide academic communities and contributes to the progress and application of science with its publication.

Other selected journals from SCIRP are listed as below. Submit your manuscript to us via either submit@scirp.org or Online Submission Portal.
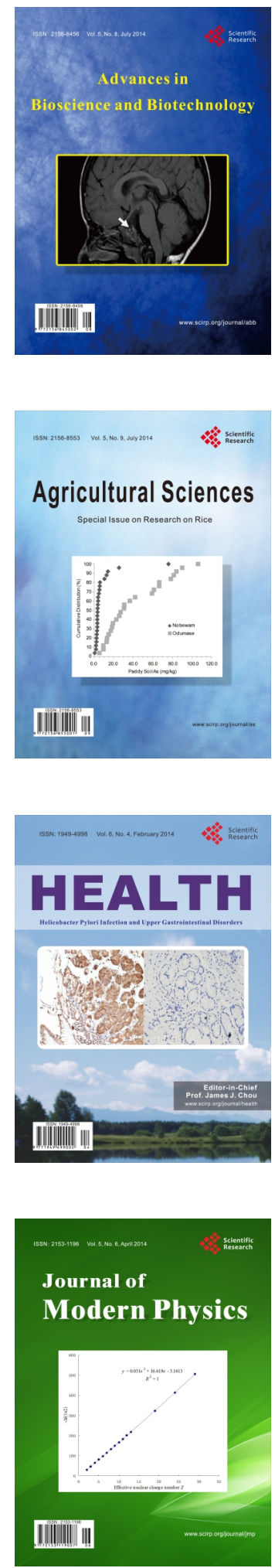
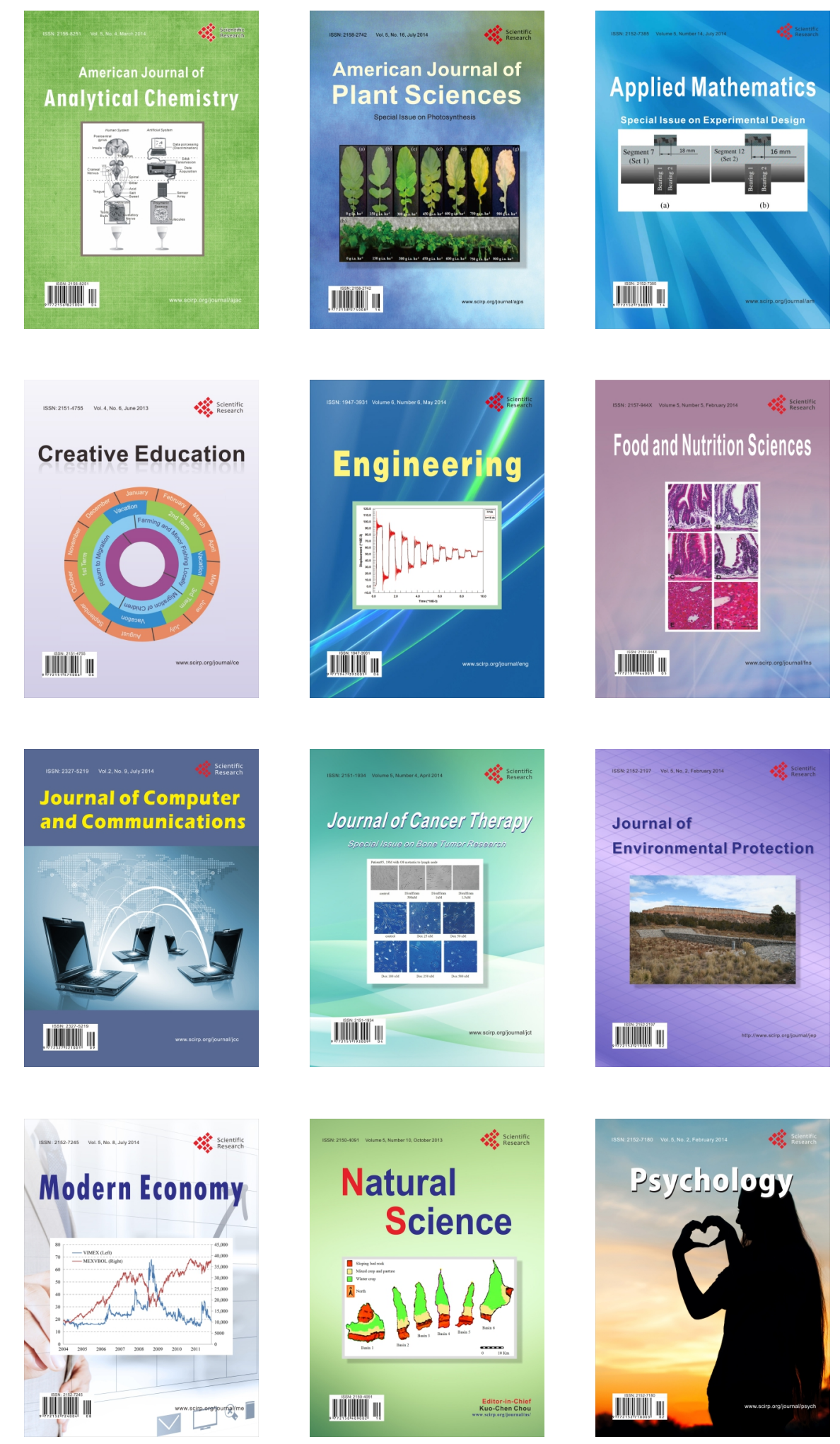